\title{
(Re)articulación de la familia contemporánea mexicana en la segunda temporada de La casa de las flores
}

\author{
Gabriel Domínguez Partida | gadoming@up.edu.mx \\ Universidad Panamericana
}

Palabras clave
"familia"; "estereotipos"; "arquetipos"; "simbo-
lismo"; "representación;" "género;" "heteronor-
matividad."
Sumario
1. Introducción
2. Estado de la cuestión y marco teórico
2.1. La lógica transnacional detrás de La casa
de las flores
2.2. El contexto social mexicano
2.3. El origen de La casa de las flores
3. Metodología
4. Definiendo a la familia mexicana según La
casa de las flores
4.1. La familia de la Mora por encima de todas
las otras
4.2. Reforzando a la familia heterosexual
nuclear
4.3. Los símbolos para enmarcar a la familia en
La casa de las flores
5. Conclusiones
6. Bibliografía

\section{Resumen}

Tradicionalmente, los contenidos audiovisuales en México han representado y reforzado un modelo de familia nuclear (padre, madre, e hijos). Sin embargo, La casa de las flores marcó un hito en esta representación al mostrar una visión alternativa de la configuración familiar, hecho enfatizado en la promoción de su segunda temporada. El programa propone redefinir y ampliar el concepto de familia a través de la inclusión de parejas LGTBIQ+, así como otros modelos. Por ello, este estudio tiene como objetivo identificar el alcance de esta redefinición en la narrativa presentada durante los nueve capítulos que integran la segunda temporada. Para lograr este propósito, se realiza un análisis textual de sus tramas, personajes y símbolos utilizados para enmarcar las relaciones familiares. El artículo concluye que, a pesar de la inclusión de configuraciones familiares distintas, prevalece un modelo biparental. Este modelo refuerza los roles maternales y paternales heredados de la representación audiovisual de la familia en México, obscurece las problemáticas vividas por otros tipos de familia y dificulta la reapropiación de símbolos que puedan facilitar el desafiar las estructuras sociales dominantes que abundan en el discurso audiovisual mexicano.

\section{Cómo citar este texto:}

Gabriel Domínguez Partida (2021): (Re)articulación de la familia contemporánea mexicana en la segunda temporada de La casa de las flores, en Miguel Hernández Communication Journal, Vol. 12(2), pp. 403 a 421 . Universidad Miguel Hernández, UMH (Elche-Alicante). DOI: 10.21134/mhjournal.v12i.1326 


\title{
Sitiados and the rewriting of the past in an identity key
}

\author{
Gabriel Domínguez Partida | gadoming@up.edu.mx \\ Universidad Panamericana
}

\author{
Keywords \\ "family"; "stereotypes"; "archetypes"; "symbolism"; \\ "representation"; "gender;" "heteronormativity." \\ Summary \\ 1. Introduction \\ 2. Status of the issue and theoretical framework \\ 2.1. The transnational logic underlaying La casa \\ de las flores \\ 2.2. The Mexican social context \\ 2.3. The origin of La casas de las flores \\ 3. Methodology \\ 4. Defining the Mexican family according to $L a$ \\ casa de las flores \\ 4.1. The de la mora family above all others \\ 4.2. Reinforcing a heterosexual nuclear family \\ 4.3. The symbols framing family in La casa de las \\ flores \\ 5. Conclusions \\ 6. References
}

\section{Abstract}

Traditionally, audiovisual content in Mexico has represented and reinforced a nuclear family model (father, mother, and children). However, La casa de las fores marked a watershed in this representation by showing an alternative vision of the family configuration, a fact stressed in its second season advertising campaign. The program proposes redefining and expanding the concept of family by including LGTBIQ+ couples and other role models. This study aims to identify the scope of this redefinition by looking at the narrative of the nine chapters that comprise the second season. A textual analysis of their plots, characters, and symbols employed by the series to frame family relationships is conducted to achieve this purpose. The article concludes that, despite the inclusion of different family configurations, a biparental model prevails. This model reinforces the maternal and paternal roles inherited from audiovisual representations of the family in Mexico, obscures problems experienced by other kinds of family, and hinders the reappropriation of symbols that may facilitate challenging dominant social structures that populate the Mexican audiovisual discourse.

Gabriel Domínguez Partida (2021): (Re)articulación de la familia contemporánea mexicana en la segunda temporada de La casa de las flores, en Miguel Hernández. Communication Journal, Vol. 12(2), pp. 403 a 421 . Universidad Miguel Hernández, UMH (Elche-Alicante). DOI: 10.21134/mhjournal.v12i.1326 


\section{Introducción}

En octubre 2019, una serie mexicana original de Netflix, La casa de las flores (Caro, 2018-2020), lanzó la campaña publicitaria de su segunda temporada. Bajo el slogan "no te metas con mi familia," la campaña presentó videos y afiches en los que se mostraban diversos personajes de la serie acompañados de flores y frases. Por ejemplo, en uno de ellos, Julián (Dario Yazbek Bernal) y Diego (Juan Pablo Medina), pareja gay en la serie, sostenían una flor. Un titulo sobrepuesto mencionaba "esto no es un hombre" y un pequeño subtitulo clarificaba, "son dos". De manera similar, en otro video, Paulina (Cecilia Suárez) y María José (Paco León), una pareja de mujeres, una de ella transgénero, abrazan una flor bajo el titulo "esto no es natural", de nueva cuenta el subtítulo contextualizaba esta frase, "obvio estamos maquilladas".

Además de que la campaña aludía y reconfiguraba una serie de frases comúnmente discriminatorias en México, el slogan "no te metas con mi familia” hacía una clara alusión al lema utilizado por el Frente Nacional de la Familia, una organización mexicana que "congrega gente que está en contra del matrimonio igualitario, adopciones homoparentales y la interrupción del embarazo, entre otras consignas” (Rodríguez, 2019: 4).

Ambos recursos sugerían al espectador el objetivo de la serie de romper la paradigmática construcción de la familia que puebla el imaginario colectivo y la representación mediática en México a través de la apropiación de frases machistas/discriminatorias y su reinterpretación. Si se observa la historia del audiovisual mexicano, es posible percatarse de que la familia ha sido uno de los constructos más referenciados. El modelo arquetípico, construido desde el final de la revolución mexicana en 1924, presenta una institución nuclear constituida por madre, padre e hijos (Gómez, 2015). La función de cada miembro es determinada por un género binario, ya sea masculino o femenino, al que se les atribuye una serie de características (Guadarrama, 2007). De esta manera, otros tipos de familias han sido poco o nulamente representadas. Este hecho opaca su inclusión en el ámbito social pues sus problemáticas y complejidades no son parte del discurso mediático, lo que las torna invisibles (Netzley, 2010).

Si bien el concepto de familia mexicana se ha redefinido al incluir familias monoparentales, sin hijos, una familia extensa con otros parientes, o una familia compuesta por personas que viven en un mismo lugar sin vínculos de sangre, la estructura patriarcal subyace en su representación mediática (Gómez, 2015). Este paradigma se ha mantenido firme en el audiovisual mexicano incluso en narrativas protagonizadas por personajes femeninos que buscan luchar por sus propios intereses (Burton-Carvajal, 1997).

Una representación constante de este modelo heterosexual nuclear contribuye a su normalización y perpetuación por la sociedad que lo produce y lo consume. Así, las narrativas mexicanas emplean una serie de símbolos que la audiencia puede identificar y relacionar como características constitutivas de la definición de familia que se 
construye en ese contexto. Esto es posible porque cada texto presenta una interacción dialógica con la audiencia en la que el evento retratado en la historia se asemeja a experiencias de la vida real (Flanagan, 2009). La correspondencia entre la representación mediática y la vida cotidiana permite que los símbolos presentados en estas narrativas prevalezcan a través del tiempo y construyan una ideología difícil de revertir (Kozin, 2009).

Una alternativa para deconstruir esa perspectiva dominante es la producción y difusión de contenidos que provean representaciones de otras realidades. Esto no implica necesariamente crear nuevas historias desde cero. Una forma de hacerlo es a través de la reformulación simbólica, similar a lo que la publicidad de La casa de las flores hiciera con las frases misóginas/homofóbicas. Es decir, es posible recurrir a los elementos que un contexto cultural emplea frecuentemente para construir un concepto y utilizarlos para definir/representar otros constructos desarticulando su carga ideológica (Suter y Daas, 2007).

La segunda temporada de La casa de las flores, desde su campaña promocional, pareciera presentar una opción discursiva distinta que apela a visibilizar otro tipo de familias, deconstruyendo la representación "tradicional" que ha permeado en el audiovisual mexicano y redefiniendo sus símbolos característicos. Para averiguar el alcance de esta meta, este artículo se centra en el análisis de las representaciones de familia que aparecen en la segunda temporada de La casa de las flores y, por consiguiente, en los símbolos utilizados para representar y reforzar/desafiar este concepto. La finalidad es identificar si el discurso promovido a través de su campaña publicitaria logra impregnar la narrativa de esta temporada y proponer un concepto más inclusivo de familia a través de la deconstrucción de sus símbolos constitutivos.

\section{Estado de la cuestión y marco teórico}

\subsection{La lógica transnacional detrás de La casa de las flores}

Aunque la publicidad de La casa de las flores presenta la serie como una producción original de Netflix, es importante señalar que es una coproducción entre dicha empresa estadounidense y la empresa mexicana Noc Noc Cinema, propiedad del realizador Manolo Caro. Debido a esta propiedad, la serie se enmarca en una dinámica transnacional que responde a los cambios surgidos de la globalización. Como García Canclini (2000) explica, uno de los muchos efectos de la globalización es superponer múltiples culturas con límites líquidos y sin un centro aparente. Además, la globalización también ha impactado en la adopción del capitalismo como sistema económico, así como la puesta en marcha de políticas neoliberales, cuyo resultado ha sido fomentar un libre mercado donde las naciones y sus ciudadanos son reemplazados por compañías y consumidores (Hermans y Dimmagio, 2007). 
Siguiendo la lógica del mercado en un panorama sin fronteras definidas donde cualquier persona puede ser un consumidor, el interés de las compañías se ha centrado en alcanzar cada vez más amplias audiencias. Sin embargo, ese objetivo requiere replantear los modelos de producción de la industria mediática y sus modelos de representación.

$\mathrm{Al}$ respecto de los modelos de producción, al intentar competir en mercados globales, las industrias mediáticas requieren una serie de alianzas estratégicas formalizadas en acuerdos de coproducción (Yong Jin, 2007). Los rasgos característicos de una coproducción son la financiación a través de un capital global, la presencia de un elenco internacional, la oportunidad de grabar en diferentes países y varios lenguajes, así como el énfasis de su estatus híbrido en su construcción formal como en su contenido narrativo (Baer y Long, 2004). Así, aunque las empresas tienen una meta en común de alcanzar una audiencia global, cada una requiere presentar atención al contexto al que responde.

Esa constante presencia de lo global y lo local en un producto mediático también se manifiesta en los modelos de representación. Siguiendo la meta de alcanzar un mercado global, las representaciones de los medios han privilegiado las historias al respecto de la naturaleza del individuo por sobre aquellas que ofrecen una mirada a los mitos fundacionales o las situaciones contextuales (García Canclini, 2000). De esa manera, se producen representaciones homogéneas que puedan alcanzar a un grupo de personas consideradas similares por la industria, a pesar de sus diferencias (Retis, 2019). Sin embargo, el contenido se enfrenta a un reto mayúsculo con la audiencia, pues los espectadores generan una mayor conexión con aquellas representaciones que les hacen reconocer su contexto del día a día (Crane, 2014).

Entonces, para ser efectiva una coproducción y servir tanto a lo global como a lo local, la alternativa más práctica es la imitación estética/narrativa de productos que son considerados exitosos internacionalmente y la incorporación de algunos rasgos contextuales a través de escenas o personajes de la cultura local (Alvaray, 2013). Por ejemplo, en la oferta mediática comercial mexicana, explica Asse Dayán (2017), prevalecen contenidos transnacionales que apelan a la construcción de arquetipos fácilmente reconocibles por un grupo más amplio de espectadores y que poco hablan de transformar las condiciones sociales del país.

De ahí que cuando el audiovisual mexicano busca adoptar representaciones de la familia, estas historias se centren más en dramas individuales que poco espacio dejan para la reflexión del trasfondo social. Martínez señala este factor como la justificación del predominio de un núcleo familiar heterenormativo en los contenidos mediáticos mexicanos, "[...] por ello muchas de las producciones del nuevo milenio insisten en presentar a la familia en su concepto tradicional, porque sigue funcionando como normalizador de la dinámica social" (2018: 32).

A pesar de ese panorama gris que parece reforzar el estatus quo, Higbee y Lim (2010)

$$
407
$$


reconocen que a través de la integración de los rasgos contextuales se puede rastrear la ideología dominante en una cultura y contrastarla con otras perspectivas operantes que también deben ser adaptadas, debido a los intereses de las compañías involucradas en la coproducción. De esa manera, la lógica transnacional provee pistas sobre la dinámica de los contextos históricos, culturales e ideológicos de una cultura en particular y su encuentro con lo global.

Esta dinámica es la que da forma y restringe la producción/representación de la familia en La casa de las flores. Por tanto, es necesario reconocer el contexto mexicano que la influye para definir la ideología operante que la serie busca desafiar.

\subsection{Contexto social}

Raza, género y clase social se entrelazan de múltiples formas en el día a día del mexicano. Si los contenidos audiovisuales coproducidos con México requieren tomar en consideración las condiciones contextuales del país para ser retratadas y desafiadas/ reforzadas en pantalla, esto quiere decir que La casa de las flores debería de incorporar algunas de las características que aquí se mencionan.

Uno de los primeros factores a considerar es la desigualdad de la distribución de la riqueza en México. La mayor parte de la población (55\%) pertenece a una clase baja donde sus ingresos apenas superan el salario mínimo en el país, $\$ 123.22$ pesos diarios; en contraste, la clase alta es apenas el $6 \%$ del número de habitantes del país. A pesar de ese hecho, el audiovisual mexicano ha encontrado su mayor éxito económico en la producción de narrativas que reflejan la vida y problemáticas de la clase alta o media-alta mexicana (Sánchez Prado, 2014).

Las particularidades de estas clases sociales representadas se manifiestan en la prevalencia de personajes de raza blanca como los protagonistas de los relatos que encarnan modelos de belleza y sofisticación, normalizando a la gente blanca como la cima de la jerarquía social (Sánchez Pérez, 2012). Esta práctica es heredada de un proceso de mestizaje en México que buscó la modernización de las comunidades indígenas a través de la adopción de "valores blancos" que suponían volverlos más "civilizados" y "aptos" para la vida en comunidad (Garner, 2007). De esa manera, la sociedad mexicana ha gestado una jerarquía en la que la raza blanca se considera casi homónima del privilegio económico y quienes no encajan con ese arquetipo deben valerse de la acumulación de bienes materiales que les permitan ser aceptados como parte de esa élite a pesar de su color de piel (Navarrete, 2016).

Por último, la identidad sexual también forma parte de esta ecuación. Si bien, como se señaló en la introducción de este artículo, el audiovisual mexicano ha privilegiado estructuras heterenormativas, la realidad del contexto mexicano no dista mucho de mantener esas estructuras como las dominantes. Ordóñez (2018) explica que la mayor discriminación expresada en México se relaciona a la identidad de género, limitando 
su acceso a distintas oportunidades educativas, laborales y sociales. Así, las minorías sexuales viven marginalizadas y son forzadas muchas veces a ocultar su identidad de género para no romper con los privilegios desprendidos de otros factores como clase social y raza. Estas tres fuerzas se materializan de distintas formas en La casa de las flores y dan forma a la construcción de familia que la serie propone.

\subsection{El origen de La casa de las flores}

Netflix produjo su primera serie mexicana en 2014, Club de Cuervos (Alazraki y Lam, 2015-2019), provocando un éxito comercial que tuvo gran aceptación en la cultura local (Tillman, 2019). Como consecuencia, la plataforma digital decidió incrementar su producción de contenido original en el extranjero. Así, el 10 de agosto de 2018, Netflix estrenó la primera temporada de La casa de las flores, una tragicomedia de 13 episodios de 25 a 35 minutos cada uno. La historia se centra en el suicidio de Roberta (Claudette Maillé) durante una fiesta de la familia de la Mora, revelando así la doble vida del patriarca Ernesto (Arturo Ríos) quien tiene una florería con su mujer y sus hijos y un cabaré con su amante, llamados ambos lugares La casa de las flores. A partir del suicidio, la familia busca mantener la imagen de perfección que poco a poco comenzará a resquebrajarse.

Durante su primera temporada, la serie dio cabida a representaciones de otros géneros sexuales desde una visión feminista, desafiando el estatus quo (Gil, 2018). Por ejemplo, reta a la sociedad machista al presentar la homosexualidad y la transexualidad como parte de la masculinidad, haciendo visible con esto a la comunidad LGTBIQ+. Sin embargo, este desafío no se extiende a la ruptura de otros paradigmas. La realidad que la serie busca retratar se circunscribe al privilegio de la raza blanca y de clase alta, convirtiéndolo en el punto de vista desde el que se busca la inclusión sexual.

La existencia de dos visiones al parecer contradictorias puede ser entendida por la lógica transnacional y de coproducción anteriormente descrita. En primer lugar, la marca Netflix se ha construido y presentado como una impulsora de la diversidad e inclusión sexual, racial y cultural, enfatizando estos elementos en la promoción de sus series, a pesar de estar inscritas en ciertas condiciones contextuales de la cultura estadounidense que las hacen limitadas (Jenner, 2018). En segundo lugar, Noc Noc Cinema, la productora de Manolo Caro, tiene una larga trayectoria de producciones mexicanas que apelan a la construcción de realidades desde un punto de vista privilegiado blanco y de clase alta como No sé si cortarme las venas o dejármelas largas (2013) y Amor de mis amores (2014), entre otras. Finalmente, la serie también adopta el formato de la telenovela mexicana que por mucho tiempo se ha caracterizado por reforzar la ideología de la clase alta y blanca mexicana (Martínez Castañeda, 2016).

La segunda temporada se estrenó el 18 de octubre de 2019, impulsada por una campaña que invitaba al espectador a involucrarse en la serie para redefinir la familia heterosexual nuclear. Los nueve capítulos de esta segunda temporada se centran en 
la muerte de Victoria (Verónica Castro) y en cómo la familia, ahora encabezada por Paulina, intenta recuperar la florería, vendida al final de la primera temporada.

\section{Metodología}

Este marco descrito sirve para dar sentido a las representaciones que brinda La casa de las Flores. Para ello este artículo se apoya en los estudios culturales que sirven para analizar las diferentes relaciones basadas en el poder entre las instituciones y la sociedad involucradas en la producción, consumo o significados de las imágenes visuales (Lister y Wells, 2001). De acuerdo con esta perspectiva, es necesario tener en cuenta los diversos factores contextuales mencionados que influyen en el espectador, el proceso de producción y la propia imagen. El resultado deseado es saber cómo la gente da sentido a esas imágenes de acuerdo con sus convenciones sociales.

La metodología utilizada para interpretar la narrativa y los personajes de la serie es el análisis textual. Los textos son constructos literarios y visuales que emplean significados simbólicos formados por reglas, convenciones y tradiciones intrínsecas al uso del lenguaje en su sentido más amplio (Hall, 1975). El análisis de un texto permite a la investigación trazar conexiones entre sus referencias simbólicas y cómo la audiencia se apropia de él y le da sentido (Brennen, 2013). Por eso el contexto proporciona las pautas para interpretar un texto.

Entonces, el estudio se centrará en el análisis de los nueve episodios de la segunda temporada de La casa de las Flores. Se presta especial atención a personajes, diálogos y hechos que se refieren directa o indirectamente al concepto de familia, se disecciona la relación que existe entre los miembros y se señala cómo ciertos elementos son usados como símbolos para representar la dinámica familiar. En consecuencia, algunos temas como la clase social resultan dependientes del concepto de familia.

\section{Definiendo la familia mexicana contemporánea se- gún La casa de las flores}

\subsection{La familia de la Mora por encima de todas las otras}

Diferentes posicionalidades convergen dentro de una familia. Una posicionalidad es un rol desde el cual un individuo interactúa con otros en un entorno social que no es estático. Así, diversas identidades convergen y median la manera en que las personas experimentan sus vivencias (Merriam et al., 2001). Siguiendo este precepto, es posible entender que, dentro de su vida familiar, una persona desempeña distintos roles, como padre, madre, hijo/a, hermano/a, etcétera. Sin embargo, otras posicionalidades también se cruzan con esos roles, como identidades sociales, provocando conflicto y negociando sistemas de privilegio, opresión, oportunidad, crisis y cambio (Few-Demo, 2014).

Antes del estreno de la temporada de La casa de las flores, su campaña publicitaria mostraba 
una serie de familias alejadas de un modelo heterosexual nuclear que ha prevalecido en México. La campaña es "una clara burla para quienes están a favor de la familia 'original', o sea papá, mamá e hijo, y que van en contra de los matrimonios igualitarios, o incluso son aquellos que no consideran familia a una mamá con sus hijos, o un papá con sus pequeños" (Martínez, 2019: 9).

Además, esta campaña publicitaria apela por la inclusión de distintas identidades sexuales al colocar personajes gay y transgénero como los protagonistas. Este hecho se refuerza al utilizar frases que comúnmente han servido como objeto de discriminación y que cuentan con una carga ideológica conservadora. Por ejemplo, una de las frases, "solo existen dos sexos," apela a la construcción heteronormativa y religiosa operante en México que señala que los dos únicos géneros que deben ser reconocidos son masculino y femenino. En consecuencia, solo pueden normalizarse las relaciones heterosexuales.

Sin embargo, el promocional va un paso más adelante al apelar a los coloquialismos mexicanos a través del subtítulo, "el mañanero y el resto." Con ello, la palabra sexo utilizada en la primera frase recibe una connotación distinta alejada de la identidad sexual y relacionada con las relaciones coitales. Esto ocurre porque en el imaginario popular mexicano el término mañanero hace referencia a un "coito al despertar" (Academia Mexicana de la Lengua, s.f.).

La reapropiación de estas frases, constante en la campaña, permite suponer que la temporada está construida de tal manera que rompe con los paradigmas al respecto de la identidad de género en el contexto mexicano. Sin embargo, cuando se observa como clase y raza son representados en la campaña, se permite vislumbrar los límites de esta empresa. Primero, todos los personajes visten ropa de diseñador y joyas, sugiriendo una clase alta. En segundo lugar, todos los personajes son blancos, incluso aquellos cuya piel es más obscura, han sido blanqueados a través de técnicas digitales para homologar un color de piel claro. Estos hechos sugieren un límite en la ruptura de paradigmas que benefician solo a las identidades sexuales de individuos de clase alta y piel blanca.

Los modelos familiares presentes en la segunda temporada de La casa de las flores brindan soporte a esta lectura. La temporada inicia en Madrid. El marco transnacional es evidente en el uso de una locación fuera de México y el uso de actores españoles como parte del elenco. Este hecho cobra un impacto más fuerte al inicio de la segunda temporada pues la serie enfatiza su intertextualidad con la teleserie española Aida (2005-2014) al integrar al elenco a otro de los actores, Eduardo Casanova, quien incluso pareciera repetir el papel de Fidel Martine: Esta intertextualidad permite comparar las prácticas sociales sobre la diversidad sexual en ambos países, pues mientras en México la identidad sexual es un tabú, en Madrid se celebra abiertamente. Al menos así lo atestigua Paulina quien sale a la terraza y entabla una conversación con este joven situado en un balcón que ostenta la bandera arcoíris.

A pesar de este marco de diversidad sexual, la noción de familia discutida durante esa primera conversación minimiza el rol que otros géneros pueden tener dentro de ella. Paulina vive con María José, su exesposo y ahora amante, y su hijo. Sin embargo, ella se lamenta de 
no poder estar con su "familia" a la que cataloga como "destruida." Para ella, el modelo nuclear es quien recibe el centro de su atención y devoción al considerar como familia solo a su madre muerta, padre y hermanos. Incluso Paulina antepone otra posicionalidad, la clase social, como un factor más relevante, al señalar su apellido, "de la Mora," como un rasgo dominante de su identidad.

Para Paulina, la carga de su apellido es símbolo de estatus y por tanto una posición social privilegiada. Esta dimensión subordina la inclusión de otras identidades sexuales para fungir un rol activo en la definición de familia. Por ejemplo, al regresar a México, María José constantemente confronta a Paulina, pidiéndole regresar a España donde ya estaban "formando una familia." Al ver estos conflictos, Bruno (Luis de La Rosa), hijo de María José y Paulina, expresa que su "familia se está desmoronando". Mientras que para Bruno y María José el concepto de familia puede ser aplicado a la relación entre una mujer, una mujer transgénero y su hijo, para Paulina, la protagonista, el término familia es solo utilizado para referirse a la estructura nuclear tradicional, en este caso su padre, madre y hermanos.

González et al. (2012) afirman que, independientemente del grado de funcionalidad de una familia, la unión y una aparente armonía entre los padres son necesarias para definir una familia en México. Esta afirmación revela una ideología heteronormativa operante en México pues reconoce un modelo heterosexual nuclear en el imaginario social. En concordancia, esto explica porque Paulina busca restaurar su unidad familiar al ocupar el lugar de su madre muerta y con ello poner en práctica el modelo de familia dominante en México. "Mi papá no está solo; él me tiene a mí", señala Paulina mientras desempeña una serie de acciones que poco a poco la colocan como la matriarca de la Mora.

El final de temporada apoya esta lectura cuando Paulina decide sacrificarse por la felicidad de su hermano, tomando el lugar de Diego en la cárcel. Este sacrificio es la máxima culminación de la devota figura materna (Gómez, 2015). A pesar de que la campaña de promoción enfatiza a María José y Paulina como un modelo diferente de familia, esto no se cumple en la historia. La relación existe, pero, debido a que la clase social es más importante, una construcción nuclear, los de la Mora, domina a cualquier otro tipo de familia que pudiera construirse.

\subsection{Reforzando a la familia heterosexual nuclear}

Así como la publicidad de La casa de las flores busca presentar a María José y Paulina como pareja y el desarrollo de la serie limita/niega esta materialización en su narrativa al favorecer una familia nuclear heterosexual, el mismo fenómeno ocurre con la relación de Diego y Julián. Al inicio de la segunda temporada, Diego y Julián han terminado. Por este hecho, Julián decide centrarse en la paternidad, pues Lucía, su exnovia, le revela que está esperando un hijo suyo. Ante la ausencia de un matrimonio, Julián demuestra su paternidad a través de su apoyo económico. Este hecho establece relación de familia entre los tres que constituye una réplica de la familia heterosexual nuclear. 
La irrupción de Diego en esta ecuación presenta una oportunidad para romper esa estructura pues abre la puerta a que se visibilicen los problemas que puede enfrentar una pareja del mismo sexo en México y a romper/transformar los arquetipos de género que el audiovisual mexicano ha perpetuado. Uno de esos arquetipos es el de la madre abnegada, dispuesta a sacrificar todo por sus hijos/familia (Gómez, 2015). Utilizando esa figura, la serie propone que Diego desempeñe ese rol al interior del relato.

Diego sufre continuamente diversas humillaciones con tal de permanecer al lado de Julián y formar una familia. De ahí que la personificación de esta actitud en Diego rompa con el arquetipo de que solo la madre es capaz de sacrificarse dentro de la familia, pero al mismo tiempo presupone, y refuerza, al sacrificio como una vía necesaria para mantener a la familia funcionando.

El problema de la alteración y apropiación de este arquetipo en la serie surge hacia el final de temporada. Aún cuando Julián y Diego han vuelto a estar juntos durante la serie, Julián quiere volver a romper su relación con Diego porque su hija (su bebé) es quién lo hace sentir completo. De acuerdo con Julián, la única forma viable para que él forme una "estructura familiar sólida" es una relación heterosexual, que, dice, será lo mejor para su hija. Sin embargo, al enterarse de que el bebé no es suyo, Julián confiesa a Diego que su sensación de plenitud provino de la creencia de tener un hijo "de su sangre". Esta revelación lleva a Diego a intentar satisfacer el deseo de Julián al consumar un encuentro sexual entre él y Elena para concebir un bebé que tenga la misma sangre que la de los de la Mora.

Aunque los de la Mora apoyan el matrimonio de Diego y Julián en el último episodio, este hecho se ve ensombrecido por una narrativa que presupone la presencia de un hijo biológico como única opción para formar una familia completa. De esta forma, aunque Diego consiga apropiarse un arquetipo de la familia heterosexual nuclear, la serie lo utiliza solo para reforzar este modelo al sugerir que, incluso en las relaciones entre el mismo sexo, siempre tiene que existir el rol de madre, padre e hijos. Aunque la trama sugiere la posibilidad de integrar otra construcción de familia, esta cae en situaciones que refuerzan previas dimensiones necesarias para imaginar a esta institución como tradicionalmente se ha hecho en las representaciones disponibles en el audiovisual mexicano.

Al colocar el foco de la serie en la familia de la Mora, los otros tipos de familia que promueve la campaña publicitaria de la segunda temporada son apenas sugerencias que se valen de arquetipos ya utilizados. En consecuencia, La casa de las flores no explora las dificultades y problemas que familias integradas por personas LGTBIQ+ experimentan y, por tanto, su representación es incompleta. Al dejar a los personajes de la comunidad LGTBIQ+ solo como posiciones sociales subyugadas a otras, la serie refuerza estereotipos sobre la comunidad, como la hiper sexualización y la promiscuidad, que son parte de un discurso heterosexual (Borgerson et al., 2006). Además, la serie enfatiza que, en el caso mexicano, la identidad sexual debe someterse a procesos de "normalización" que les permita encajar en los arquetipos que integra una familia heterosexual nuclear. 


\subsection{Los símbolos para enmarcar a la familia en $\mathrm{La}$ casa de las flores}

Como se expresó en el apartado anterior, todas las relaciones en pareja confluyen en la familia de la Mora y en la construcción de una familia heterosexual nuclear. Sin embargo, así como la publicidad de esta segunda temporada se apropió de algunas frases discriminatorias para revertir su significado y expandir el de familia, La casa de las flores intenta hacer lo mismo con algunos de los símbolos utilizados en el relato y sugerir lecturas que amplían el concepto de familia.

La motivación de Paulina durante el inicio de la temporada es recuperar la florería a toda costa. Para ella, este lugar se convierte en el único vínculo con su madre y recuperarlo significa mantener unida a su familia. Los lugares juegan un papel vital en la definición de la propia identidad pues dan pistas al respecto de cómo una persona socializa con el mundo físico (Twigger-Ross y Uzzell, 1996). Un lugar sirve como referente de experiencias previas, parte del reconocimiento propio, que influye en nuestra autoeficacia. Las personas vinculan la preservación de estos lugares a una tradición generacional que da sentido a la identidad individual (Chen, 2011). De ahí que Paulina encuentre en la florería la conservación de todas las tradiciones inherentes a su familia. Este lugar representa su conexión con su abuela, su madre y su presente como un continuo.

La florería se convierte en un lugar que vincula a los personajes en una dinámica familiar. Representa no solo a la madre ausente, sino que también simboliza el linaje de los de la Mora. Conectar un lugar, como esta florería, con el duelo familiar permite a la audiencia comprender la alteración de los roles dentro de la familia, su cohesión como grupo y la transformación de un espacio en un hogar, pues solo ahí pueden ser ellos mismos. Tercero (2002) explica que, ante el duelo familiar, los miembros de este grupo buscan una conexión afectiva más cercana y redistribuyen los roles para tomar el lugar del miembro fallecido, fenómeno que explica el nuevo rol de Paulina como matriarca de la familia.

Cumpliendo los argumentos de Tercero (2002), Micaela demuestra su necesidad de una conexión afectiva más cercana con los demás miembros de la familia utilizando la florería como excusa para provocar esta unión. Cabe señalar que el hecho de que Micaela es hermanastra de los de la Mora la hace sentir excluida de esa dinámica familiar. Es por ello por lo que Micaela utiliza la florería, un espacio con gran carga simbólica para el grupo de hermanos sanguíneos, como motivación para participar en un concurso de televisión en el que el premio económico servirá para recuperar el negocio familiar. De esa forma, Micaela busca ser aceptada a través de la "compra" de su lugar en esta familia.

Sin embargo, la florería no es el único lugar que representa la unidad familiar. Duran- 
te esta temporada, la mansión de los de la Mora cobra relevancia al servir como un espacio recurrente en el que los personajes se desenvuelven y dan sentido a la familia. Elena, por ejemplo, desayuna de forma habitual en este lugar, aunque, como señala Julián, "tiene su propia casa". Sin embargo, para los personajes de La casa de las flores, un hogar y una casa no son lo mismo. El hogar es ese lugar donde los miembros de una familia experimentan la definición de su individualidad al mismo tiempo que este lugar les ayuda a construir un significado que define su unidad (Doyle, 1992).

Por ello, la transgresión de este hogar es una amenaza para esa unidad. Así, cuando Ernesto decide que La Parvada, una secta religiosa, pueda mudarse a la mansión luego de que Jenny Quetzal (Mariana Treviño) lo eligiera como su "esposo", este hecho desplaza a los hijos de Ernesto de sus roles al interior de la familia, por ello Paulina "ya no lo reconoce". Al permitir que una nueva familia acceda a la mansión, Ernesto suplanta la familia nuclear con una compuesta. La serie propone una restauración del orden familiar una vez que los de la Mora logran desalojar a La Parvada. Aun así, durante la presencia de La Parvada en ese lugar, el espectador puede presenciar como la dinámica de la secta se modifica gracias a ese espacio para convertirse en una familia donde la cooperación de todos los miembros es necesaria.

Aunque la apropiación este espacio por una familia compuesta parezca fomentar la inclusión de otros tipos de familias, cabe señalar que el hecho de que Jenny y Ernesto deban "convertirse en esposos" mientras los demás miembros son considerados como hijos, indica que la estructura heterosexual nuclear sigue prevalente. Lo mismo ocurre en otro espacio que se construye como hogar, el cabaré, pues Paulina lo dirige en sociedad con Diego, cumpliendo ambos el rol de madre y padre respectivamente. De esa forma, aunque los espacios puedan resignificarse al incluir otros géneros sexuales su límite sigue siendo la familia heterosexual nuclear.

Es quizá un segundo símbolo el que permite expandir la definición de familia: el anillo de bodas de la abuela. Suter y Daas (2007) identifican que las parejas del mismo sexo usan anillos para representar su compromiso y desafiar las estructuras heteronormativas. Siguiendo ese ejemplo, la serie refuerza el valor social que se ha dado a este símbolo al usarlo para formalizar los compromisos entre personajes. Este objeto, al ser heredado de generación en generación, adquiere una carga simbólica más compleja. Curasi et al. (2004) explican que la función de estos objetos heredados dentro de una familia es representar la esencia de esa institución y llevan toda su mitología. Así, cuando los individuos realizan esta acción de heredar objetos familiares, están manteniendo las unidades familiares más cohesionadas, proporcionando identidad familiar, haciendo distinciones de estatus y representando valores morales y religiosos.

De esta forma, la amplitud del concepto de familia se produce cuando se le entrega el anillo a Julián para que formalice su relación con Diego. Con esta acción, los personajes no solo aceptan y normalizan la unión de una pareja gay, sino que, al transferirles la mitología generacional, el espectador también reconoce que una configuración familiar también puede tomar esa forma. Es decir, aquí la identidad sexual se antepone 
a otras posicionalidades como clase social, enfatizando que es más importante la identidad de género que un apellido.

Sin embargo, aun cuando el símbolo sea utilizado en la serie para incluir otro tipo de uniones que distan de la familia tradicional, las normas operativas de sus miembros, que replican previos roles de las relaciones heterosexuales nucleares y, el dejar de lado las problemáticas específicas de estas relaciones, establecen los límites del propósito de adoptar estos símbolos como una forma de desafío al discurso ideológico dominante.

\section{Conclusiones}

La segunda temporada de La casa de las flores se promocionó a través de un discurso que parece desafiar al núcleo familiar configurado por padre, madre e hijos constante en el audiovisual mexicano. Un análisis más detenido de las tramas que se desarrollan durante los episodios que conforman esta temporada revela una propuesta menos abrupta que la indicada por la publicidad. Si bien la serie incluye relaciones de pareja entre personas identificadas como parte de la comunidad LGTBIQ+, las múltiples realidades que estas parejas/familias presentan se obscurecen por otras posicionalidades que hacen prevalecer una estructura heterosexual nuclear que refuerza la ideología imperante en la sociedad mexicana.

La narrativa logra visibilizar a estas comunidades, pero sus problemáticas como el matrimonio, la adopción, o los retos de ser reconocidos como familia, están ausentes en el discurso de inclusión que la serie busca promover. No basta con hacerlos visibles, también es fundamental centrarse en el papel que estos personajes ocupan en el discurso social, sus relaciones con las estructuras dominantes y la representación de los diversos problemas que enfrentan en diferentes circunstancias.

Una forma de lograr este objetivo es reconfigurar los símbolos utilizados para reforzar un discurso heteronormativo, como el anillo o los espacios. El uso de estos símbolos puede desafiar el discurso público y ampliar su significado. De ahí que este hecho transfiera connotaciones simbólicas inclusivas a estas comunidades y sus miembros, como sugieren Suter y Daas (2007).

La segunda temporada de La casa de las flores pone de manifiesto la necesidad en el audiovisual mexicano de construir nuevas formas de pensar a la familia en la sociedad mexicana contemporánea. Una situación que se convierte en imperante en un contexto transnacional en el que los productos mediáticos no solo se consumen al interior de un país, sino que son llevados a todo el mundo gracias a las plataformas digitales. La redefinición de la familia hacia la configuración de un modelo inclusivo a través de las representaciones mediáticas es todavía un trabajo en progreso que al menos se pone en discusión con narrativas como la aquí presentada. 


\section{Bibliografía}

Academia Mexicana de la Lengua (s.f.). Mañanero y Matutino. Academia Mexicana de la Lengua. Recuperado de https://bit.ly/3h3Pwx3

Alvaray, L. (2013). Hybridity and genre in transnational Latin American cinemas. Transnational Cinemas, 4(1), 67-87. doi: 10.1386/trac.4.1.67_1

Asse Dayán, J. (2017). Güeros: Social Fragmentation, Political Agency and the Mexican Film Industry under Neoliberalism. Norteamérica, 137-68. doi:10.20999/nam.2017.a005.

Baer, H., y Long, R. F. (2004). Transnational Cinema and the Mexican State in Alfonso Cuarón's Y tu mamá también. South Central Review, 21(3), 150-168. doi: https://doi. org/10.1353/scr.2004.0031.

Borgerson, J. L., Schroeder, J. E., Blomberg, B., y Thorssén, E. (2006). The gay family in the ad: Consumer responses to non-traditional families in marketing communications. Journal of Marketing Management, 22(9-10), 955-978. doi: 10.1362/026725706778935646

Brennen, B. (2013). Qualitative research methods for media studies. New York: Routledge.

Burton-Carvajal, J. (1997). Mexican Melodramas of Patriarchy: Specificity of Transcultural Form. En A.M. Stock (Ed.), Framing Latin American Cinema: Contemporary Critical Perspectives (pp. 186-240). Minneapolis: Uinversity of Minnesota Press.

Chen, F. (2011). Traditional architectural forms in market oriented Chinese cities: Place for localities or symbol of culture? Habitat International, 35(2), 410-418. doi: https://doi. org/10.1016/j.habitatint.2010.11.012

Crane, D. (2014). Cultural globalization and the dominance of the American film industry: cultural policies, national film industries, and transnational film. International journal of cultural policy, 20(4), 365-382. doi: 10.1080/10286632.2013.832233

Curasi, C. F., Price, L. L., y Arnould, E. J. (2004). How individuals' cherished possessions become families' inalienable wealth. Journal of consumer research, 31(3), 609-622. doi: $10.1086 / 425096$

Doyle, K. O. (1992). The symbolic meaning of house and home: An exploration in the psychology of goods. American Behavioral Scientist, 35(6), 790-802. doi: $10.1177 / 0002764292035006013$

Few-Demo, A. L. (2014). Intersectionality as the "new" critical approach in feminist family studies: Evolving racial/ethnic feminisms and critical race theories. Journal of Family Theory y Review, 6(2), 169-183. doi: 10.1111/jftr.12039 
Flanagan, M. (2009). Bakhtin and the movies: new ways of understanding Hollywood film. New York: Springer.

García Canclini, N. (2000). Industrias culturales y globalización: procesos de desarrollo e integración en América Latina. Estudios internacionales, 90-111. Recuperado de https://bit. ly/3jg4CCy

Garner, S. (2007). Whiteness: an introduction. London: Routledge.

Gil, E. A. (2018, 23 agosto). 'La casa de las flores': la serie de Netflix que tiene hasta un \#Challenge viral. Harper's Bazaar, México, agosto. Recuperado el 6 de junio de 2021 en https://bit.ly/3dcBcRG

Gómez, C.E. (2015). Familia y Estado. Visiones desde el cine mexicano. Guadalajara: Universidad de Guadalajara.

González, M. E., Dávalos, C., y Gutiérrez, M. (2012). Modern Family y los mensajes culturales: percepciones de jóvenes receptores mexicanos de la serie televisiva estadounidense. Comunicación, 10. Recuperado de https://bit.ly/3wWvgnV

Guadarrama, L. A. (2007). Familia y medios de comunicación. Pistas para pensar en la investigación. Espacios Públicos, 127-149. Recuperado de https://bit.ly/3h4dHM2

Hall, S. (1975). Introduction. En A. Smith, E. Immirzi, y T. Blackwell (Eds.), Paper voices: The popular press and social change, 1972-79 (pp. 128-138). London: Hutchinson.

Higbee, W., y Lim, S. H. (2010). Concepts of transnational cinema: towards a critical transnationalism in film studies. Transnational Cinemas, 1(1). doi: 10.1386/trac.1.1.7/1

Hermans, J., y Dimaggio, G. (2007). Self, identity, and globalization in times of uncertainty: A dialogical analysis. Review of general psychology, 11(1), 31-61. doi: 10.1037/10892680.11.1.31

Jenner, M. (2018). Netflix Marketing: The binge and diversity. En M. Jenner (Ed.), Netflix and the re-invention of television. Cambridge: Palgrave Macmillan.

Kozin, A. (2009). The appearing memory: Gilles Deleuze and Andrey Tarkovsky on crystal-image. Memory Studies, 2(1), 103-117. doi: 10.1177/1750698008097398

Lister, M. y Wells, L. (2001). Seeing beyond belief: cultural studies as an approach to analyzing the visual. En T. van Leeuwen y C. Jewitt (Eds.), Handbook of visual analysis. (pp. 61-91). London: Sage.

Martínez Castañeda, B. J. (2016). Las tres Marías. Thalia y el sueño de la blanquitud. Docu- 
mento presentado en el Seminario del Pensamiento Español: Todos los mundos posibles: series de televisión y filosofía, Ciudad de México, México. Recuperado de https://bit. ly/3hc3vRM

Martínez, Y. N. (2018). La familia y su representación en la pantalla cinematográfica nacional. En A. Ortiz y M. Femat (Coord.), Estudios de familias (pp. 19-38). Ciudad de México: Universidad Autónoma Metropolitana.

Martínez, N. (2019, 18 octubre). La casa de las flores 2, oda a la doble moral. Vanguardia, México, agosto. Recuperado 6 de junio de 2021: https://bit.ly/3jfNaOf

Merriam, S. B., Johnson-Bailey, J., Lee, M. Y., Kee, Y., Ntseane, G., y Muhamad, M. (2001). Power and positionality: Negotiating insider/outsider status within and across cultures. International Journal of Lifelong Education, 20(5), 405-416. doi: 10.1080/02601370120490 Navarrete, F. (2016). México racista: una denuncia. Ciudad de México: Grijalbo.

Netzley, S. B. (2010). Visibility that demystifies: Gays, gender, and sex on television. Journal of homosexuality, 57(8), 968-986. doi: 10.1080/00918369.2010.503505

Ordóñez, G. (2018). Discriminación, pobreza y vulnerabilidad: los entresijos de la desigualdad social en México. Región y sociedad, 30(71). doi:10.22198/rys.2018.71.a377

Retis, J. (2019). Homogenizing Heterogeneity in Transnational Contexts: Latin American Diasporas and the Media in the Global North. En J. Retis y R. Tsagarousianou (Eds.), The Handbook of Diasporas, Media, and Culture (pp. 115- 136). Hoboken: Wiley-Blackwell.

Rodríguez, A. (2019, 8 octubre). Netflix y La casa de las flores retan la homofobia del Frente Nacional por la Familia y. Mercad2.0, México, agosto. Recuperado 6 de junio de 2021 de: https://bit.ly/3dgor8R

Sánchez Prado, I. (2014). Screening Neoliberalism: Transforming Mexican Cinema, 1988-2012. Nashville: Vanderbilt University Press.

Sánchez Pérez, J. A. (2012). Pigmentocracia y medios de comunicación en el México actual: la importancia de las representaciones socio-raciales y de clase en la televisión mexicana. Documento presentado en el Congreso Internacional “América Latina: La autonomía de una región,” Madrid, España. Recuperado de https://bit.ly/3xY0Fqf

Suter, E. A., y Daas, K. L. (2007). Negotiating heteronormativity dialectically: Lesbian couples' display of symbols in culture. Western Journal of Communication, 71(3), 177-195. doi: $10.1080 / 10570310701518443$

Tercero, R. (2002). Duelo familiar. Sistemas familiares, 18(1-2), 48-61. Recuperado de https://bit.ly/3vYNILj 
MHJournal Vol. 12 (2) | Año 2021 - Artículo no 19 (186) - Páginas 403 a 421 - mhjournal.org

Tillman, L. (2019, 19 marzo). Netflix, atraído por el talento, impulsa la producción en México de 50 películas y series. Los Angeles Times, México, agosto. Recuperado 6 de junio de 2021 de https://lat.ms/3depfeB

Twigger-Ross, C. L., y Uzzell, D. L. (1996). Place and identity processes. Journal of environmental psychology, 16 (3), 205-220. doi: https://doi.org/10.1006/jevp.1996.0017

Yong Jin, D. (2007). Reinterpretation of cultural imperialism: Emerging domestic market vs. continuing US dominance. Media, Culture \& Society, 29(5), 753-771. doi: 10.1177/0163443707080535 


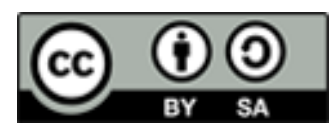

Licencia Creative Commons

Miguel Hernández Communication Journal

mhjournal.org

\section{Cómo citar este texto:}

Gabriel Domínguez Partida (2021): (Re)articulación de la familia contemporánea mexicana en la segunda temporada de La casa de las fores, en Miguel Hernández. Communication Journal, Vol. 12(2), pp. 403 a 421 . Universidad Miguel Hernández, UMH (Elche-Alicante). DOI: 10.21134/mhjournal.v12i.1326 